\title{
HIV prevalence in patients with sexually transmitted diseases in Yaounde, (Cameroon) in 1989 and 1990: necessity of an STD control
} programme

\author{
L Zekeng, D Yanga, A Trebucq, D Sokal, R Salla, L Kaptue
}

\begin{abstract}
Objective-To monitor HIV seroprevalence among STD clinic attenders as part of a sentinel surveillance programme.

Design-Seroepidemiological survey on randomly selected patients.
\end{abstract}

Setting-"Elig Essono" STD clinic, Yaounde; from February 1989 to December 1990.

Patients-1161 randomly selected patients.

Main outcome measures-HIV and syphilis seroprevalence.

Results-Twenty six of the 1161 patients (2.4\%; CI: 95\%; 1.5\%-3.3\%) tested were found to be HIV positive (mostly due to HIV1); $35.4 \%$ had antibodies to Treponema pallidum. There was no association between HIV seropositivity and sex, marital status, or educational level. Genital ulcer disease did not correlate with HIV seroprevalence. However, patients with a positive serological test for $T$ pallidum were more likely to have HIV infection (rr $=2 \cdot 4 ; 95 \% \mathrm{CI}$; from $1 \cdot 1$ to $3 \cdot 0)$. Results from 1990 were double those of $1989(3.3 \%$ versus $1.6 \%, p=0.02)$. Conclusions-Compared with the findings among the same groups in metropolitan areas of various other African countries, the HIV seroprevalence is still low; this could be due to many reasons, such as the recent introduction of the virus in the country, a different spectrum of STDs, the high level of circumcision of males. HIV infection trends should continue to be monitored among risk groups such as STD patients and control programmes implemented to reduce the rapid spread of AIDS in the country.

\section{Introduction}

Infection with human immunodeficiency virus (HIV) in adults in Africa is predominantly due to heterosexual transmission. The first studies of acquired immunodeficiency syndrome (AIDS) in Central Africa identified prostitutes and heterosexually promiscuous men as high risk groups. ${ }^{1}$ There is mounting evidence, however, that sexually transmitted diseases (STDs) may be important cofactors for enhancing HIV transmission. ${ }^{12}$ Therefore patients attending STD clinics should be con- sidered a high risk group for HIV infection. Cameroon is located in the Central African region where AIDS is endemic. Different surveys carried out in the country have shown surprisingly low but slowly increasing HIV1 seroprevalence: $0.4 \%$ among blood donors in Yaounde in 1987, 0.9\% in 1988 and $1 \%$ in $1989^{3}(7 \%$ among prostitutes in Yaounde in $1988^{4}$, versus $9 \%$ in $1990 .{ }^{5}$ However there is a scarcity of information concerning HIV infection in patients with STDs in Cameroon. We conducted a study among STD clinic attenders in Yaounde to assess this issue.

\section{Methods}

Population: Study participants were randomly selected between February 1989 and December 1990 (an average of 50 monthly) among patients attending the "Centre medico-social d'Elig Essono", the largest centre in Yaounde (800,000 inhabitants) dedicated mostly to the treatment of STDs (6000 to 7000 patients per year). Each patient had a history taken and an examination performed; sociodemographic information was obtained by means of a standard questionnaire. Blood $(10 \mathrm{ml})$ was drawn from each patient for syphilis serology and the results were given to the patient. The specimens were then tested in an anonymous unlinked basis for HIV1 and HIV2 antibodies. The classification of STDs was made on clinical findings.

Laboratory methods: Laboratory tests included for syphilis: the rapid plasma reagin test (RPR from Becton and Dickinson) and the Treponema pallidum hemagglutination assay (TPHA from MILES). A positive sample on RPR was quantified by TPHA and considered positive at a dilution more or equal to $1 / 160$. Serum was tested for HIV1 and HIV2 antibodies by a commercial enzyme linked immunosorbent assay (ELISA) (Enzygnost HIV1, 2 Behring); a positive sample was tested again by a specific ELISA (Enzygnost HIV1 and Clonatec HIV2) followed by a virus specific WESTERN BLOT on repeatedly reactive samples (IgG HIV1 Biotechnology and Lav blot 2 for HIV2). Samples were confirmed as positive for HIV if bands corresponding to at least two envelope proteins were visualised. Synthetic peptides (Peptilav) were used to discriminate dual confirmed reactivity (HIV1 + HIV2).

Statistical methods: Data entry using Dbase3 Plus was carried out by experienced operators 
Table 1 HIV Ab and STS status according to age

\begin{tabular}{|c|c|c|c|c|c|}
\hline \multirow[b]{2}{*}{ Age (years) } & \multirow[b]{2}{*}{ No } & \multicolumn{2}{|c|}{$H I V+$} & \multicolumn{2}{|c|}{$R P R / T P H A+$} \\
\hline & & No & $\%$ & No & $\%$ \\
\hline $\begin{array}{l}15-19 \\
20-24 \\
25-29 \\
30-34 \\
35-39 \\
40-44 \\
45+\end{array}$ & $\begin{array}{r}140 \\
437 \\
324 \\
147 \\
45 \\
30 \\
38\end{array}$ & $\begin{array}{r}2 \\
7 \\
12 \\
5 \\
1 \\
0 \\
1\end{array}$ & $\begin{array}{l}1.4 \\
1.6 \\
3.7 \\
3.4 \\
2.2 \\
0 \\
2.6\end{array}$ & $\begin{array}{r}48 \\
123 \\
125 \\
64 \\
18 \\
16 \\
16\end{array}$ & $\begin{array}{l}34 \cdot 3 \\
28 \cdot 1 \\
38 \cdot 6 \\
43 \cdot 5 \\
40 \\
53 \cdot 3 \\
42 \cdot 1\end{array}$ \\
\hline Total & 1161 & 28 & $2 \cdot 4$ & 410 & 35.4 \\
\hline
\end{tabular}

and entries were rechecked by a second operator. Analysis was done using Epi Info version 5 .

\section{Results}

Between February 1989 and December 1990, 1161 Cameroonian patients were recruited (579 patients in 1989 and 582 patients in 1990). Table 1 also shows their age distribution. Seventy-three percent were male (all circumcised) and $27 \%$ were female. Ninety-seven percent were living in an urban area and only $3 \%$ were from rural areas. The most common STDs were urethritis $(41 \%)$, secondary syphilis $(28 \%)$, and genital ulcers $(9 \%)$. No disease was found in $9 \%$ of the patients consulting because of a suspicion of an STD. Overall, $2.4 \%$ were seropositive for HIV infection $(1.6 \%$ in 1989 , CI $95 \%: 1.6 \%$, SD $1 \%$ versus $3.3 \%$ in 1990 , CI $95 \%: 3.3 \%$, SD $1.4 \%$ ); $2.3 \%$ of the patients were HIV1 reactive; none reacted to HIV2 and $0.09 \%$ reacted to both viruses. Table 2 compares selected indexes of demographic and HIV status. There was no significant relationship between HIV infection and sex. Nor did the marital status, the educational level, and the current clinical STD status correlate with HIV seropositivity. The HIV seroprevalence was $2 \cdot 1 \%$ in patients with urethritis, $3.4 \%$ in those with secondary syphilis, $0.9 \%$ in patients with genital ulcers and $2 \%$ in patients with other STDs (see table 3 ). The seroprevalence of syphilis was $35.4 \%$ (34.5\% in 1989 versus $37.1 \%$ in 1990 ). Patients with a positive syphilis serology were more likely to be seropositive for HIV than patients with a negative serology $(3.8 \%$ versus $1.6 \%$;rr $=2 \cdot 4 ; 95 \%$ CI from $1 \cdot 1$ to $5 \cdot 0$ ). Table 1 shows the distribution of positive cases (HIV and syphilis) according to age groups.

Table 2 Demographic characteristics of 1161 patients according to HIV status

\begin{tabular}{|c|c|c|c|c|}
\hline Characteristic & $\begin{array}{l}H I V+ \\
(n=28)\end{array}$ & $\begin{array}{l}H I V- \\
(n=1133)\end{array}$ & $\%$ & $\operatorname{rr}(95 \% C I)$ \\
\hline $\begin{array}{l}\text { Sex: } \\
\text { Male } \\
\text { Female }\end{array}$ & $\begin{array}{r}20 \\
8\end{array}$ & $\begin{array}{l}828 \\
305\end{array}$ & $\begin{array}{l}2 \cdot 4 \\
2 \cdot 6\end{array}$ & $0.9(0.4-2 \cdot 1)$ \\
\hline $\begin{array}{l}\text { Matrimonial status } \\
\text { Single } \\
\text { Other }\end{array}$ & $\begin{array}{l}17 \\
11\end{array}$ & $\begin{array}{l}731 \\
402\end{array}$ & $\begin{array}{l}2 \cdot 3 \\
2 \cdot 7\end{array}$ & $0.9(0.4-1.8)$ \\
\hline $\begin{array}{l}\text { Syphilis: } \\
\text { RPR -TPHA + } \\
\text { RPR - TPHA- }\end{array}$ & $\begin{array}{l}16 \\
12\end{array}$ & $\begin{array}{l}400 \\
733\end{array}$ & $\begin{array}{l}3.9 \\
1.6\end{array}$ & $2 \cdot 4(1 \cdot 1-5 \cdot 0)$ \\
\hline
\end{tabular}

rr: relative risk; $\mathrm{CI}$ : confidence interval; Other ${ }^{\star}$ : married, divorced, free union, etc.
Table 3 Sexually transmitted diseases according to HIV status

\begin{tabular}{|c|c|c|}
\hline Disease & $\%$ & HIVI positive \\
\hline $\begin{array}{l}\text { Urethritis }(n=471) \\
\text { Secondary syphilis }(n=328) \\
\text { Genital ulcers }(n=105) \\
\text { Vaginal discharge }(n=51) \\
\text { Other STDs } \text { ST }^{\star}(n=101)\end{array}$ & $\begin{array}{c}41 \\
28 \\
9 \\
4 \cdot 4 \\
8 \cdot 9\end{array}$ & $\begin{array}{cl}10^{\star} & (2 \cdot 1 \%) \\
11 & (3 \cdot 4 \%) \\
1 & (0.9 \%) \\
2 & (3.9 \%) \\
2 & (2 \%)\end{array}$ \\
\hline Total $(n=1056)$ & & $26 \quad(2 \cdot 5 \%)$ \\
\hline
\end{tabular}

*One case was also reactive for HIV2.

Other STDs ${ }^{\star}$ : pelvic inflammatory disease; condyloma; genital herpes; balanitis.

\section{Discussion}

In this study we detected HIV antibody among 1161 patients attending the STD clinic in Yaounde over a period of 23 months, as part of a sentinel surveillance programme. The overall prevalence of HIV infection was $2 \cdot 4 \%$. We did not find any significant association between HIV infection, sex, marital status, or educational level. Clearly, the seroprevalence of HIV infection is low compared with the findings among the same groups in metropolitan areas of various other African countries: $21 \%$ in Abidjan, (Cote d'Ivoire), $28 \%$ in Butare (Rwanda), $29 \%$ in Lusaka (Zambia) and $18 \%$ in Nairobi (Kenya). ${ }^{13}$ Several factors may contribute to our low prevalence findings: Firstly they could be because HIV was recently introduced into Cameroon, and the epidemic is just following its normal course, which was not observed in other countries because surveillance did not begin until late in the epidemic. Secondly, HIV prevalence levels could be low because there is a different spectrum of STDs in Cameroon compared with that found in East and Southern Africa. In Cameroon, chancroid is rare, whereas in those countries which have experienced the fastest spread of HIV, chancroid is very common and is the most common cause of genital ulcer. Many data ${ }^{26}$ suggest that chancroid is extremely effective at increasing female to male transmission of HIV. In the absence of chancroid, epidemic spread of HIV may be significantly slower. Third, there is a very high level of circumcision of males in Yaounde: $100 \%$ of clinic attenders were circumcised. Several studies have suggested that circumcision is an important risk factor for HIV transmission. ${ }^{7}$ Fourth, Cameroon began initiation of control measures at a very early stage of the epidemic. Cameroon began a programme for targetted distribution of condoms to high risk groups in 1986, a programme which has since been greatly expanded and has been very successful. In addition, not all STD patients attended the "Elig Essono" clinic, even though it is the only STD clinic in Yaounde. However, we do not believe this factor significantly biased our results.

Nine percent of the patients did not have an STD after examination; there was no significant difference of HIV seroprevalence between patients with a diagnosed STD and those without an STD $(2.5 \%$ versus $2 \%)$, but we should clearly define the populations to be studied for sentinel surveillance, otherwise 
wrong conclusions could be drawn from HIV infection seroprevalence among STD clinic attenders.

In our study, HIV infection was not associated with clinical genital ulcers as previously described in data from Cote d'Ivoire and East Africa. ${ }^{26891011}$ Nevertheless, a positive serological test result for $T$. pallidum was correlated with HIV seropositivity ( $\mathrm{rr}=$ 2.4 ) as shown in numerous studies; ${ }^{26}$ by calculations, the attributable fraction of HIV infection due to the effect of syphilis acting as a co-factor is $33 \%$. We believe markers for syphilis could be associated with a past history of genital ulcer.

Twenty eight patients were found HIV positive; among them, 27 were HIV1 and 1 who dually reacted (HIV1 + HIV2). Our study provides support for the predominance of HIV1 in Central Africa. HIV testing was done on an anonymous and unlinked basis and we could not carry out more investigations on the patient who reacted to both viruses; however, the chances that this case could be indigenous are slim. In a recent survey on HIV2 infection in Cameroon, 9 samples out of 13,517 were found to be HIV2 reactive with 2 cases of dual reactivity; ${ }^{12}$ six of the HIV2 positive cases have had some West African connections, and no information was available on the three other cases.

When we look at the HIV seroprevalence in 1989 and 1990 in Cameroon, the result has significantly doubled $(1.6 \%$ versus $3.3 \%$, p value of $z$ test $=0.02$ ). This trend is important and the 1991 results are expected to be much more significant; even though HIV seroprevalence is still low, the number of AIDS cases is increasing. The situation may become worse. A concrete, simple, efficient and nationwide STD control programme should be established urgently. STD clinic attenders with a diagnosis of STD should be monitored continuously for HIV infection trends in the ongoing sentinel surveillance program, to follow the evolution of the disease on risk groups.

\section{Conclusions}

Between 1989 and 1990, 1,161 STD patients were screened for HIV and syphilis in Yaounde. There was no association between HIV infection and the current STD status, especially with genital ulcers disease as described in many studies; however, a positive serological test for $T$. pallidum was strongly correlated with HIV seropositivity. HIV seroprevalence is still low in Cameroon compared with some African countries. STD patients should be considered as risk groups. STD control programmes especially aimed at heterosexually promiscuous subjects must be implemented to slow the rapid spread of HIV infection in Cameroon.

We are indebted to AIDSTECH/Family Health International (Durham, North Carolina, USA) for their invaluable support to the AIDS control service.

1 Kreiss J, Carael M, Meheus A. Role of sexually transmitted diseases in transmitting human immunodeficiency virus. Genitourin Med 1988;64:1-2.

2 Pepin J, Plummer F, Bruhman R, et al. The interaction of HIV infection and other sexually transmitted diseases: an opportunity for intervention. AIDS 1989;3:3-9.

3 Kaptue L, Zekeng L, Monny-Lobe M, et al. Blood donor data as a monitor of HIV1 trend in Yaounde. Abstract No TPE 40; Vth international conference on Aids in Africa 1990, Kinshasa, Zaire.

4 Kaptue L, Zekeng L, Djoumessi S, et al. HIV and Chlamydia infections among prostitutes in Yaounde, Cameroon. Genitourin Med 1991, 67;2:143-5.

5 Kaptue L, Zekeng L, Tchoffo M, et al. HIV infection and syphilis infections among prostitutes in Yaounde between 1988 and 1990. Abstract No TRTD5; Vth international 1988 and 1990. Abstract No TRTD5; Vth internation

6 Piot P, Laga M. Genital ulcers, other sexually transmitted diseases, and the sexual transmission of HIV: the first two may be important risk factors for the third. $B J M$ 1989;298:623-4.

7 Simonsen JN, Cameron DW, Gakinya NM, et al. Human immunodeficiency virus infection among men with sexually transmitted diseases. Experience from a center in Africa. The New England Journal of Medicine 1988; 319:274-8.

8 WHO: Global Programme on Aids and Programme of Std. Consensus statement from consultation on sexually transConsensus statement from consultation on sexually trans-
mitted diseases as risk factor for HIV transmission. AIDS 1989; vol 2, no 3:248-55.

9 Diallo MO, Ackah AN, Porter A, et al. HIV1 and HIV2 infections in Abidjan STD clinics. Abstract No FOA6. infections in Abidjan STD clinics. Abstract No FOA6. Kinshasa, Zaire.

10 Haverkos $\mathrm{H}$, Edelman $\mathrm{R}$. The epidemiology of acquired immunodeficiency syndrome among heterosexuals. JAMA 1988, 260;13:1922-9.

11 Latif AS, Katzenstein DA, Bassett MT, et al. Genital ulcers and transmission of HIV among couples in Zimbabwe. AIDS 1989;3:519-23.

12 Zekeng L, Pinay P, Barth P, et al. HIV2 infection in Cameroon: No evidence of indigenous cases. 1992, Journal of Acquired Immune Deficiency Syndromes (in press).

13 Piot P, Kreiss JK, Achola et al. Editorial review: Heterosexual transmission of HIV. AIDS, 1987;1:199-206. 